\title{
Management Interventions and Public Health Policies: Prevention, Control and Palliative Care in Oncology
}

\author{
Clevson Santos Passos ${ }^{1}$, Erica Regina Ribeiro Sady ${ }^{2}$, and Clevia Santos Passos ${ }^{3 *}$ \\ ${ }^{1}$ Post-Graduate Program, Health Management with Emphasis on Hospital Administration, Faculdade Estacio, \\ Aracaju, SE, Brazil.
}

${ }^{2}$ Department of Cardiovascular Pulmonary Physiotherapy, Hospital BP, Beneficencia Portuguesa de Sao Paulo, Sao Paulo, SP, Brazil.

${ }^{3}$ Department of Cardiopneumology, Instituto do Coracao, Faculdade de Medicina da Universidade de Sao Paulo, Sao Paulo, SP, Brazil.

\section{${ }^{*}$ Corresponding author:}

\section{Clevia Santos Passos}

Department of Cardiopneumology, Instituto do Coracao, Faculdade de Medicina da Universidade de Sao Paulo, Sao Paulo, SP, Brazil.

Received : June 11, 2019

Published : July 1, 2019

\section{INTRODUCTION}

Politics plays a critical role in matters relating to health or the treatment of chronic diseases such as cancer. It is important that health professionals working for the government in research and health sectors or in health support groups understand the political dimensions of the problems and solutions proposed in order to collaborate with leaders in public health interventions with forecasting and opportunities for change in the short term and long term in society [1-3]. Public health research and practice have contributed to an increase in life expectancy, which includes basic sanitation, prevention and cessation of tobacco use, control of infectious diseases by immunization, prevention of injuries and other interventions, as well as opportunities are still needed to improve the health of the population, preferably adopting

\section{ABSTRACT}

The benefits of public policy actions and interventions in preventive and curative health services facilitate the well-being and care of the health and quality of life of cancer patients. The purpose of this narrative review was to contextualize the importance of management intervention and public health policies in lifestyle and in relation to disease prevention, health promotion and palliative care in cancer. The search was performed in PubMed and Scielo databases. Our results show that actions and evidence-based interventions facilitate action professionals in social policy and public health, as well as intervention programs that sought to solve problems in the lifestyle of society and quality of life in cancer patients. Thus, even with the challenges in the implementation of preventive actions and health promotion, management interventions and health policies are essential to enable care and insertion of effective health care programs in oncology.

KEYWORDS: Cancer; Health Management; Public Policy; Life Style; Quality of Life; Palliative Care.

evidence-based strategies $[1,3,4]$.

Through scientific research, professionals act from the knowledge and understanding of the causes and consequences of illness, disability and death along with policy agents $[5,6]$. Thus, public policies take place through a set of programs, actions, goals and decisions taken by governments together with the participation of the public and private sector to ensure the well-being of society and public interest [5-7]. Socioeconomic, cultural, ethnic, environmental, work, lifestyle, age, heredity conditions also determine the health of society $[7,8]$.

Actions and preventive interventions in clinical and community settings need to be evidence-based and need to be planned and implemented to improve health [1]. The dissemination 
and implementation of actions, even if specific, should be considered, such as political challenges, financing, training of people, so these issues may need some adaptation to suit the contextual conditions of each place to be implemented [1]. It is possible to learn to create environments that add comfort and health, as well as to increase the diversity of activities to be carried out [9]. As cancer patients' survival has increased, cancer treatment costs tend to raise the cost and impact on public health, the incentive to follow healthy and preventive habits may contribute to cost-effectiveness with interventions which aim to promote change in lifestyle $[10,11]$.

\section{Cancer and Lifestyle}

In the preventive and control of chronic diseases such as cancer, changes to improve the lifestyle have been encouraged as an investment to reduce some costs from educational actions, disease prevention, health promotion and effective interventions to change unhealthy lifestyle habits [12]. Thus, people are expected to increase physical activity, healthy eating, stop using tobacco, reduce alcohol consumption, and promote health rehabilitation and improved quality of life [12].

Smoking is responsible for most cancers of the lung, oropharynx, larynx, and esophagus, but due to the circulation of tobacco components, use affects other organs distant from the directly affected site, such as the kidneys, liver, pancreas, and urinary bladder [13]. For patients who stop smoking during and after cancer treatment they have a higher chance of survival and reduce the risk of mortality compared to those who continue to smoke $[14,15]$.

The combination of multidimensional approaches and educational, clinical and social strategies for prevention and cessation of tobacco use increase public health goals $[16,17]$ in the following categories: 1 . policies (including price increases, reduced access to tobacco products, advertising bans); 2. health promotion and education (anti-tobacco advertising campaigns, messages on social networks); 3. cessation interventions (use of means for counseling and cessation therapy, drugs approved by the organs monitoring and control of food and medicines); 4. monitoring and evaluation; 5. training for procedures and administration and management [17-19].

The promotion of health from cause-effect knowledge, favors the prevention of the main causes of death, incapacity and diseases, among them, some types of cancer, cardiovascular diseases, pulmonary diseases and liver cirrhosis, discovery of specific factors present in the environment physical (carcinogenic, radiation), and social (tobacco use, fatty diets, alcohol consumption, physical inactivity), in relation to the social, these can be considered modified lifestyle factors [12].

Changing cancer-related behavior after diagnosis, recurrence or survival needs more evidence, but several research findings show the importance of healthy lifestyle, healthy eating, and regular physical exercise in reducing cardiovascular and metabolic diseases, and also in reducing symptoms of fatigue and depression, side effects common to cancer survivors, so patients should be encouraged to plan and follow paths to improve health and prevent health risks [20].

Cancer survivors tend to increase adipose body mass and sometimes reduce lean mass after chemotherapy, however, this can reduce quality of life, functional capacity, increase cancer recurrence and even death [21-24]. As overweight and obesity are increasing worldwide, individualized dietary counseling, and programs focused on body mass control, and inclusion of physical exercises for cancer survivors are interventions that tend to be most effective for overall health and function physics [20,24-29].

The benefits of exercise are associated with an improvement in the prognosis and survival of cancer patients [30-32]. Exercise programs have improved physical fitness and metabolic, psychosocial aspects and have shown effects at primary and tertiary levels in cancer prevention by improving the inflammatory system, sex steroids (estrogens, progestagens and androgens), adiponectin, leptin glucose metabolism and insulin, however, more randomized clinical studies on cancer recurrence are still needed [32-39].

Cancer is considered a growing disease worldwide. Scientific advances in early detection and treatment efficacy have transformed the disease considered fatal in curable disease for some individuals; however, treatment and side effects have caused pain, depression and fatigue in some patients. Thus, before and after the survival of the cancer there should be a concern with the quality of life related to the health of the individuals who receive the diagnosis of cancer, as well as, offer quality in care and treatment. In addition to prevention, cancer control and early detection actions, the policy should contribute to improving the quality of life of individuals, provide appropriate treatment, and use palliative care $[7,40]$.

\section{Palliative Care in Oncology}

Despite the advances in the care of patients with oncological diseases, the multidimensional impact of these diseases is still 
worrying. It is estimated that these individuals experience 8-12 symptoms that, in addition to being underdiagnosed, may be subtreated $[41,42]$. In addition, it is believed that, with population aging, increased global cancer incidence and more effective treatment, coexistence of potentially limiting health conditions is almost inevitable. Therefore, it is not reasonable to consider providing curative treatments for cancer patients, but mainly palliative care aimed at minimizing the associated suffering, from the diagnosis to the terminal stage of oncologic disease progression [43].

Palliative care, then, consists of a philosophy of care that addresses all dimensions of suffering (physical, mental, emotional, social, and spiritual) to which vulnerable patients with the diagnosis of diseases threatening life [43]. However, it is important to note that this approach should not be restricted to the terminal phase. Palliative care can and should be instituted since diagnosis, and maintained (with increasing and progressive relevance) in coexistence with curative interventions [44].

These care may be offered at the primary, inpatient or community level, with a basic approach based on universal principles of good health practice; at the secondary level, with extensive and targeted evaluation and interventions in hospitals, specialized clinics or the community; and finally. At the tertiary level, where, in addition to extensive evaluation, intensive management from complex interventions, instituted by specialists in specialized palliative care units, with the expansion of this knowledge to the academic, teaching and research environment [44].

There is evidence that the multidimensional and multiprofessional approach improves the quality of life and symptom control of cancer patients. It is also known that it promotes the reduction of health costs, public and private, especially at the end of life, when there is a tendency to institute futile treatments, which disregard values of the patient and his family, potentially causing suffering [45-48].

When made available early, it allows the individual to understand about their disease and the prognosis; about risks and benefits of treatments; reduce suffering secondary to disease in any dimension; prevent and manage unpleasant symptoms such as pain, anorexia, cachexia, nausea, dyspnea, fatigue, insomnia, pruritus, among others [43,44]. Develop strategies to deal with fear, anxiety, stress and bereavement; spiritual support and for the individuals that make up the support network of the central characters (family, caregivers, friends, among others) $[43,44]$.

In addition, the early approach to palliative care allows early planning of an advanced care plan. So, knowing the possibilities of disease progression, you can choose specific treatments (or refusal), as well as where you want to receive them, (hospital, hospices or at home), among other aspects, in order to access care that is compatible with their perception of quality of life, and that their autonomy and dignity are preserved and respected, especially when they cannot exercise them for any reason [49].

Thus, the impact of the disease on symptoms, the use of inappropriate (futile) and potentially aggressive therapies, unnecessary visits to specialized health centers, and hospital admissions can be reduced, especially in the intensive care setting [50].

\section{CONCLUSIONS}

Health research can assist in the management and formulation of public policies, which may contribute to health gains and longevity of society. In addition, medical and other health care professionals (physiotherapists, physical education professionals, nurses, nutritionists, among others) together with policymakers can lead to prolonged survival with better quality of life through some serious illnesses and better palliative care with prevention and relief from the suffering imposed by the disease. Therefore, it is essential to implement short-term, long-term actions for disease prevention, to promote improved social and economic conditions, lifestyle, increased health promotion actions, control and appropriate treatments of cancer, will contribute to the improvement of the quality of life of sick individuals as well as of society in general.

\section{REFERENCES}

1. Brownson RC, Fielding JE, Maylahn CM (2009) Evidencebased public health: A fundamental concept for public health practice. Annu Rev Public Health 30: 175-201.

2. Kemm J (2001) Health impact assessment: A tool for Healthy Public Policy. Health Promot Int 16(1): 79-85.

3. Roper WL, Koplan JP, Stinnett AA (1994) Public health in the new American health system. Front Health Serv Manage 10(4): 32-36.

4. Madans JH, Makuc DM (2000) Health, United States, 2000; with Adolescent health chartbook. 
5. Oliver TR (2006) The politics of public health policy. Annu Rev Public Health 27: 195-233.

6. Hanney SR, Gonzalez-Block MA Buxton MJ, Kogan M (2003) The utilisation of health research in policy-making: Concepts, examples and methods of assessment. Health Res Policy Syst 1(1): 2.

7. WHO (2002) New cancer report offers hope for patients and communities. WHO, Geneva, Switzerland.

8. Marmot MG (1998) Improvement of social environment to improve health. Lancet 351(9095): 57-60.

9. Caldwell LK (1963) Environment: A new focus for public policy? Pub admin Rev 23: 132-139.

10. Neumann A, Lindholm L, Norberg M, Schoffer O, Klug SJ, Norstrom F (2017) The cost-effectiveness of interventions targeting lifestyle change for the prevention of diabetes in a Swedish primary care and community based prevention program. Eur J Health Econ 18(7): 905-919.

11. Armstrong EP (2010) Prophylaxis of cervical cancer and related cervical disease: $A$ review of the cost-effectiveness of vaccination against oncogenic HPV types. J Manag Care Pharm 16(3): 217-230.

12. Terris M (1992) Concepts of health promotion: Dualities in public health theory. J Public Health Policy 13(3): 267-276.

13. Brambilla E, Travis WD (2014) Lung cancer, World Cancer Report. [Stewart BW, Wild CP, eds], Lyon Cedex, France, 350-631.

14. Florou AN, Gkiozos IC, Tsagouli SK, Souliotis KN, Syrigos KN (2014) Clinical significance of smoking cessation in subjects with cancer: A 30-year review. Respir Care 59(12): 1924-1936.

15. Parsons A, Daley A, Begh R, Aveyard P (2010) Influence of smoking cessation after diagnosis of early stage lung cancer on prognosis: Systematic review of observational studies with meta-analysis. BMJ 340: b5569.

16. Global activities of the National Center for Chronic Disease Prevention and Health Promotion (NCCDPHP). (2002). Centers for Disease Control and Prevention, Promot Educ, USA, 9, 155, 165, 175-156.

17. Institute of Medicine (US) Committee on smoking cessation in military and veteran populations; Bondurant S, WR, editors. (2009) Combating Tobacco Use in Military and Veteran Populations. Washington (DC): National Academies Press (US). Appendix A, effective tobaccocontrol programs.

18. CDC. Best practices for comprehensive tobacco control programs-2007. (2007) Atlanta, GA. National center for chronic disease prevention and health promotion, Office on smoking and health.

19. WHO (2007) Protection from Exposure to Second-Hand Tobacco Smoke. Policy Recommendations, WHO, Geneva, Switzerland.

20. Demark-Wahnefried W, Jones LW (2008) Promoting a healthy lifestyle among cancer survivors. Hematol Oncol Clin North Am 22(2): 319-342, viii.

21. Brown JK, Byers T, Doyle C, Coumeya KS, DemarkWahnefried W, Grant B, et al. (2003) Nutrition and physical activity during and after cancer treatment: An American Cancer Society guide for informed choices. CA Cancer J Clin 53: 268-291.

22. Herman DR, Ganz PA, Petersen L, Greendale GA (2005) Obesity and cardiovascular risk factors in younger breast cancer survivors: The Cancer and Menopause Study (CAMS). Breast Cancer Res Treat 93(1): 13-23.

23. Chlebowski RT, Aiello E, McTiernan A (2002) Weight loss in breast cancer patient management. J Clin Oncol 20(4): 1128-1143.

24. Rock CL, Demark-Wahnefried W (2002) Nutrition and survival after the diagnosis of breast cancer: A review of the evidence. J Clin Oncol 20(15): 3302-3316.

25. Demark-Wahnefried W, Aziz NM, Rowland JH, Pinto BM (2005) Riding the crest of the teachable moment: promoting long-term health after the diagnosis of cancer. J Clin Oncol 23(24): 5814-5830.

26. Jones LW, Demark-Wahnefried W (2006) Diet, exercise, and complementary therapies after primary treatment for cancer. Lancet Oncol 7(12): 1017-1026.

27. Goodwin P, Esplen MJ, Butler K, Winocur J, Pritchard K, Brazel S, et al. (1998) Multidisciplinary weight management in locoregional breast cancer: Results of a phase II study. Breast Cancer Res Treat 48(1): 53-64.

28. Demark-Wahnefried W, Peterson BL, Winer EP, Marks L, Aziz N, Marcom PK, et al. (2001) Changes in weight, body composition, and factors influencing energy balance 
among premenopausal breast cancer patients receiving adjuvant chemotherapy. J Clin Oncol 19(9): 2381-2389.

29. Smith MR (2003) Changes in body composition during hormonal therapy for prostate cancer. Clin Prostate Cancer 2(1): 18-21.

30. Ligibel J (2012) Lifestyle factors in cancer survivorship. J Clin Oncol 30(30): 3697-3704.

31. Vijayvergia N, Denlinger CS (2015) Lifestyle factors in cancer survivorship: Where we are and where we are headed. J Pers Med 5(3): 243-263.

32. Schmitz KH, Courneya KS, Matthews C, DemarkWahnefried W, Galvao DA, Pinto BM, et al. (2010) American College of Sports Medicine roundtable on exercise guidelines for cancer survivors. Med Sci Sports Exerc 42(7): 1409-1426.

33. Kampman E, Vrieling A, van Duijnhoven FJ, Winkels RM (2012) Impact of diet, body mass index, and physical activity on cancer survival. Curr Nutr Rep 1: 30-36.

34. Winzer BM, Whiteman DC, Reeves MM, Paratz JD (2011) Physical activity and cancer prevention: A systematic review of clinical trials. Cancer Causes Control 22(6): 811-826.

35. Ulrich CM, Wiskemann, J, Steindorf, K. (2012) Physiologic and molecular mechanisms linking physical activity to cancer risk and progression. Bundesgesundheitsblatt Gesundheitsforschung Gesundheitsschutz 55(1): 3-9.

36. McTiernan A (2008) Mechanisms linking physical activity with cancer. Nat Rev Cancer 8(3): 205-211.

37. Strasser B, Steindorf K, Wiskemann J, Ulrich CM (2013) Impact of resistance training in cancer survivors: a metaanalysis. Med Sci Sports Exerc 45(11): 2080-2090.

38. Courneya KS, Tamburrini AL, Woolcott CG, McNeely ML, Karvinen KH, Campbell KL, et al. (2011) The alberta physical activity and breast cancer prevention trial: Quality of life outcomes. Prev Med 52(1): 26-32.

39. Friedenreich CM, Woolcott CG, McTiernan A, Ballard-Barbash R, Brant RF, Stanczyk FZ, et al. (2010) Alberta physical activity and breast cancer prevention trial: Sex hormone changes in a year-long exercise intervention among postmenopausal women. J Clin Oncol 28(9): 1458-1466.
40. WHO (2007) Palliative care. Cancer control: knowledge into action-WHO guide for effective programmes. Module 5. WHO, Geneva, Switzerland.

41. Portenoy RK, Thaler HT, Kornblith AB, Lepore JM, Friedlander-Klar H, Coyle N, et al. (1994) Symptom prevalence, characteristics and distress in a cancer population. Qual Life Res 3(3): 183-189.

42. Chang VT, Hwang SS, Feuerman M, Kasimis BS (2000) Symptom and quality of life survey of medical oncology patients at a veterans affairs medical center: A role for symptom assessment. Cancer 88(5): 1175-1183.

43. WHO Definition of Palliative Care. www.who.int/cancer/ palliative/definition/en (last accessed 05/03/2002).

44. Hui D, Hannon BL, Zimmermann C, Bruera E (2018) Improving patient and caregiver outcomes in oncology: Team-based, timely, and targeted palliative care. CA Cancer J Clin 68(5): 356-376.

45. May P, Normand C, Cassel JB, Del Fabbro E, Fine RL, Menz $\mathrm{R}$, et al. (2018) Economics of palliative care for hospitalized adults with serious illness: A meta-analysis. JAMA Intern Med 178(6): 820-829.

46. Smith S, Brick A, O'Hara S, Normand C (2014) Evidence on the cost and cost-effectiveness of palliative care: $A$ literature review. Palliat Med 28(2): 130-150.

47. Smith TJ, Cassel JB (2009) Cost and non-clinical outcomes of palliative care. J Pain Symptom Manage 38(1): 32-44.

48. Willmott L, White B, Gallois C, Parker M, Graves N, Winch S, et al. (2016) Reasons doctors provide futile treatment at the end of life: A qualitative study. J Med Ethics 42(8): 496-503.

49. Hoerger, M, Greer JA, Jackson VA, Park ER, Pirl WF, ElJawahri $A$, et al. (2018) Defining the elements of early palliative care that are associated with patient-reported outcomes and the delivery of end-of-life care. J Clin Oncol 36(11): 1096-1102.

50. Jang RW, Krzyzanowska MK, Zimmermann, C, Taback N, Alibhai SM (2015) Palliative care and the aggressiveness of end-of-life care in patients with advanced pancreatic cancer. J Natl Cancer Inst 107(3): pii: dju424 DOI: 10.1093/ jnci/dju424. 